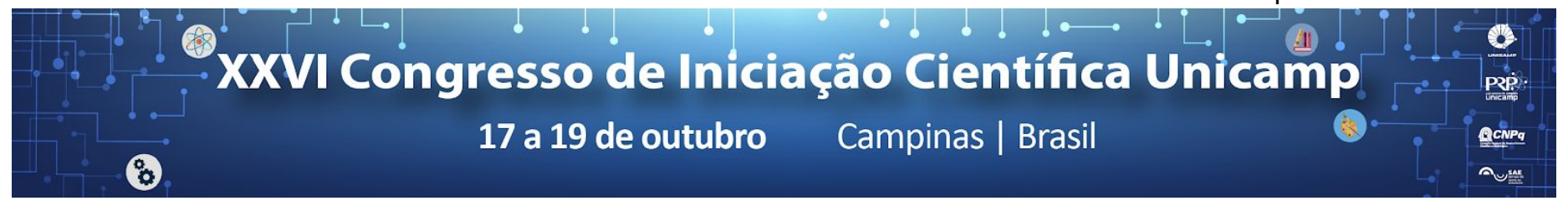

\title{
Desenvolvimento de formulação cosmética contendo extrato de mirtilo (Vaccinium ashei) para proteção solar e combate ao envelhecimento da pele
}

\section{Júlia G. Franco *, Letícia Cefali, Priscila G. Mazzola}

\section{Resumo}

Os filtros solares são formulações capazes de proteger a pele contra raios UV, que causam diferentes danos à pele, sendo que os estudos com substâncias naturais, como o mirtilo, visam diminuir a irritação causada por alguns filtros solares. Por apresentarem alto teor de flavonóides e antocianinas, o mirtilo pode ser estudado como uma possível alternativa no desenvolvimento deste tipo formulações cosméticas.

\section{Palavras-chave:}

Mirtilo, fator de proteção solar, antioxidante.

\section{Introdução}

A exposição a raios ultravioletas (UV) são a principal causa de câncer de pele e do envelhecimento precoce (OSTERWALDER et al., 2000). Os filtros solares são formulações cosméticas que apresentam a capacidade de proteger a nossa pele contra raios solares, principalmente raios UV, sendo uma medida preventiva contra o surgimento de câncer de pele (INCA, 2006).

Estudos com substâncias de origem natural, como o mirtilo (Vaccinium ashei), têm mostrado uma possível ação contra a radiação UV, devido a presença de flavonoides, associados à atividade antioxidante das antocianinas, combatendo o envelhecimento precoce (ACEVEDO et al., 2005; GOLDMEYER et al., 2014).

Portanto, o objetivo deste estudo é desenvolver uma formulação cosmética estável que contenha extrato de mirtilo rico em antocianinas, e avaliar o fator de proteção solar e atividade antioxidante in vitro do extrato e da formulação.

\section{Resultados e Discussão}

Para a produção do extrato do mirtilo, as frutas foram lavadas, submetidas à estufa por 4 dias, trituradas em um liquidificador comum e tamisado. Posteriormente, foi preparado o extrato hidroalcoólico utilizando uma solução hidroalcoólica $60 \%$ (1:3).

O extrato hidroalcoólico foi submetido a alguns testes, como FPS in vitro, identificação de antocianinas, $\mathrm{DPPH}$ e ABTS. $\mathrm{O}$ extrato apresentou um FPS in vitro igual a 34,6 e $76 \mathrm{mg}$ de antocianinas totais $/ 100 \mathrm{~g}$ de fruta.

Nos teste de atividade antioxidante in vitro, o extrato apresentou uma porcentagem de inibição máxima de $88,8 \%$ no DPPH e $99,86 \%$ de inibição no ABTS.

Figura 1. Teste atividade antioxidante ABTS e DPPH
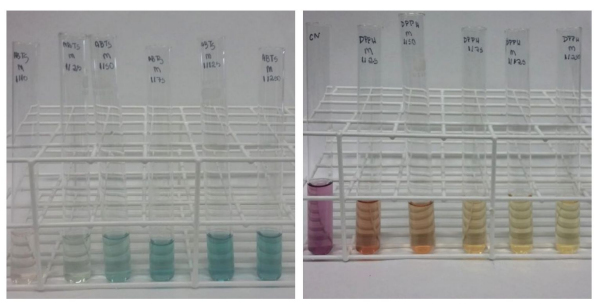

formulação contendo o extrato microencapsulado. $O$ creme foi submetido ao estudo de estabilidade, avaliando o $\mathrm{pH}$, densidade, viscosidade, FPS e atividade antioxidante (DPPH) in vitro das emulsões.

Figura 2. Formulação com extrato livre e com microcápsulas do extrato

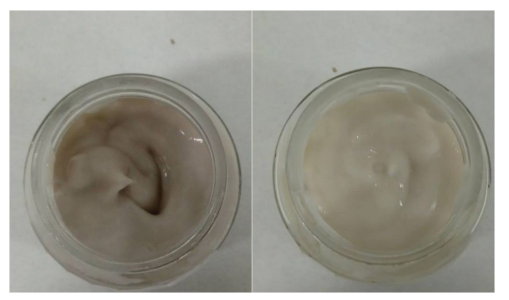

As emulsões foram colocadas em 5 ambientes diferente. No dia 0 a emulsão com o extrato livre apresentou FPS in vitro igual a 3,75 e uma porcentagem de inibição de $79 \%$, enquanto a emulsão com a microcápsula apresentou um FPS in vitro igual a 1,36 e um porcentagem de inibição de $35 \%$. Estas características serão avaliadas durante os dias $7,15,30,45,60$ e 90.

\section{Conclusões}

Foi possível concluir que o extrato do mirtilo apresenta flavonóides, FPS e atividade antioxidante in vitro, podendo ser utilizado em formulações cosméticas para a proteção da pele causado pelos raios UV e no combate ao envelhecimento precoce.

\section{Agradecimentos}

Agradecimentos ao PIBIC, Capes, CNPq e FAPESP.

1. ACEVEDO, JGA; CASTANEDA, C.M.C.; BENITEZ, F.J.C.; DURÁN, D.A.; BARROSO, V.R.; MARTINEZ, C.G.; MUNOZ, L.J.L.; MARTINEZ, C.A.; ROMO de VIVAR, A. Photoprotective activity of Buddleja scordioides. Fitoterapia.v.76, n. 3-4, p.301-309, 2005.

2. GOLDMEYER et al., Características físico-químicas e propriedades funcionais tecnológicas do bagaço de mirtilo fermentado e suas farinhas. Rev. Bras. Frutic., v. 36, n. 4, p. 980-987, 2014.

3. INCA. Instituto Nacional de Câncer. A Situação do Câncer no Brasil. Rio de Janeiro: Instituto Nacional do Câncer, p. 42-45, 2006.

4. OSTERWALDER, U.; LUTHER, H.; HERZOG, B.; Cosmet. Toil. (Ed. Port.)12, 52, 2014.

A partir destes dados, foi desenvolvido uma formulação cosmética contendo o extrato a $2 \%$ e outra 